\title{
Human Parainfluenza Virus 3
}

National Cancer Institute

\section{Source}

National Cancer Institute. Human Parainfluenza Virus 3. NCI Thesaurus. Code C112317.

The serotype labeled 3 of the viral species Human parainfluenza virus, which is a singlestranded, neg ative-sense RNA virus of the Paramyxoviridae family and Respirovirus genus, and causes croup and respiratory infections in humans. 